㾞料

\title{
二重線質量差と原子質量との表 I
}

\author{
緒 方 惟 一 \\ （大阪大学理学部物理学教室）
}

元素の原子量は周知のよろに早くより綕ての元素に 対して測定されていたし，また原子質量一個個の同 位体の質量を $160=16.000000$ として測定した值一 るその測定がはじめられたのは遠くかの有名な Aston (1925 年) にさかのぼるのであるが 300 近い同位体の ろち,とにかく（精度はしばらくおくとして）原子質量 の測定されていたすの蜘年前までその $1 / 4$ にす満 たないありさまであつた。しかもその測定值は精度悪 く，またいいろの測定上のあやまりす見逃されてい たような状態であつだ。これには種種の原因が考えら れるがその最大のあのは，それまでは原子質量の測定 は総て同一原理の質量分析器に依存し，またそれらの 分解能む低かつたこと（実験的分解能 10,000 以下） によると考えられる。すなわち同一形式の装置におい ては同一種類の系統的誤差を起し易く，したがつて測 定値相互の比較によつてそれを発見することが困難な 場合が多く，自然見逃され勝ちになつていた。また分 解能の低かつたために導入された誤まりは，イオン源 内に怙いては予期しないイオンが往往生成されること によると考えられる。すなわちそれらがたまたを測定 すへき二重線の成分と装置の分解能以下の質量差しか 持たないときには測定すべき線間隔の読みに誤まりを きたすこととなる。このよろな原因から今次大戦前の 測定值には多くの訂正すべきすのが含まれていると考 えねばならぬ。以上のよろなことが発見されたつは次 のような事情による。すなわち戦後原子核反応の反応 エネルギーの測定が磁場または電場分析器によつて非 常に精密に行われ得るよろになり，また測定された反 応の種類も多くなつて, これらを適当に組合せること により, 質量分䉼器による測定值を全然用いずに独立 に原子質量を算出し得ることとなつた。またその精度 も質量分析の方より得られるるのと同程度になり，そ の結果両者の比較が可能となつて, 両測定值の間にそ れぞれの㒭差の数倍の開きのあるすのがいくつあある ことが発見されるようになつた。その一二の例を挙げ
ると，原子質量決定の基礎となるいわわる質量補助標 準である $1 \mathrm{H}, 2 \mathrm{D}$ を算出する際に主役を演ずる $\mathrm{1H}_{2}-2 \mathrm{D}$ 二重線の質量差が両測定において大きな喰い違いを示 すことが見出された。すなわら数年前まではこの值と して 1938 年の Mattauch のあの (15.39 $\pm 0.021_{1}\left(10^{-4}\right.$ $\mathrm{amu})$ ) が決定版と考えられていたが，1951 年核反㢁

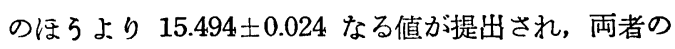
開きは放置することができないこととなつだ。また 方 $2 \mathrm{D}_{2}-4 \mathrm{He}$ 二重線質量差において子質量分析の方 よりは $256.1 \pm 0.4\left(10^{-4} \mathrm{amu}, 1937\right.$ 年 BainbridgeJordanの值)が得られていたが核反広よりは $255.0 \pm$ 0.23 (1950 年) となり，これまたこの開きは誤差の 4 〜5 倍となり看過しえないすのとなつた。このような 事情のもとで質量分析の面に批いては導入される危険 性のある系統的誤美についての慎重な実験的研究が行 われ，一方装置の幾何学的調整を非常に精密化するこ そによつてその分解能を戦前の数倍以上 (現在の最高 は〜100,000 (Mattauch 1954 年)) に向上せしめるこ とに成功, 1950 年頃より各地で二重線質量差の再測 定, 新測定が開始された。また従来原子質量の湘定 はもつぱら啠量分析器が使用されていたが，Nier 等 は二重收斂質量分析計を用いて原子質量決定に成功, さらに最近 (1953) に㧊いては Smith 等はタイム オブーフライトの原理を用いた彼のいわゆるマスシン クロメーターを完成, 従来の 2 3 倍の精度をすつて 二三の二重線質量差の測定を行つている。このように 質量分析の面においても原理を異にした装置による測 定が開始されたが，一方核反広奏験においてす慎重に 測定が繰返され後の表に見られる如く現在測定されて いる範囲に拈いては（核反広の方においてはそれのみ で独立に質量決定を行いうるのは現在硫黄まで） ${ }^{12} \mathrm{C}$ $\mathrm{H}_{4}-16 \mathrm{O}$ 二重線質量美を除いて両者はかなりよい一致 を示すにいたつた。そして前記の例の $\mathrm{H}_{2}{ }^{2} \mathrm{D}$ につい: ては核反応よりの值が正しく， ${ }^{2} \mathrm{D}_{2}-4 \mathrm{He}$ については質 量分析よりの值が正しかつたことが判明した。しかし 

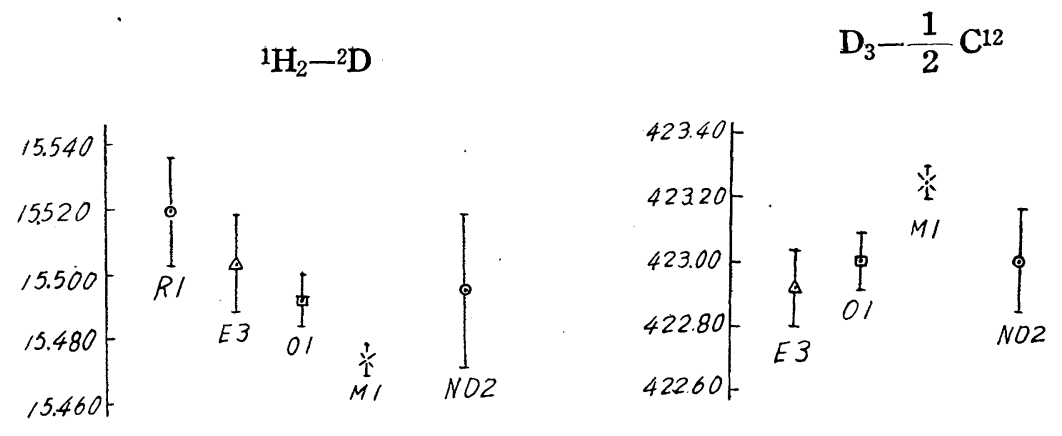

只

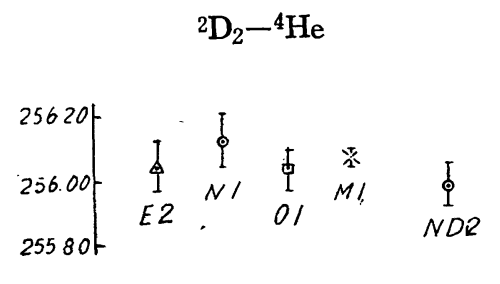

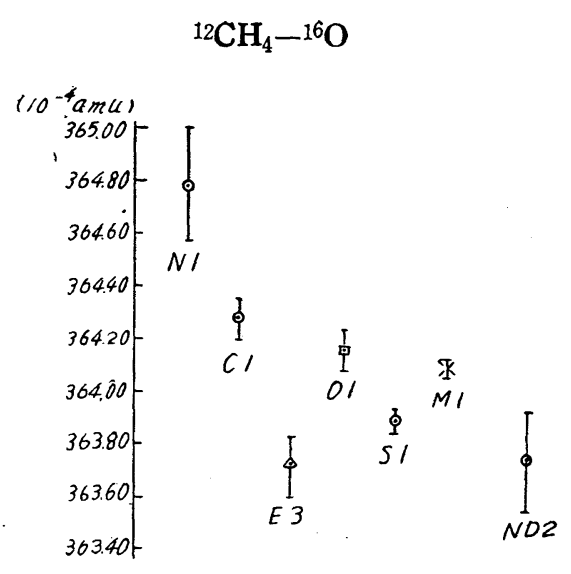

R 1: Roberts, Phys. Rev. 81, 624 (1951)

E 3 : Ewald, Z. Naturforsch. 6a, 293 (1951)

O 1 : Ogata Matsuda, Phys. Rev. 89, 27 (1953)

M 1 : Mattauch 'Bieri, Private commanication (1954, Feb.)

ND2: Li, Phys. Rev. 88, 1038 (1952)

N 1 : Nier Roberts, Phys. Rev. 81, 507 (1951)

C 1 : Collins et al, Phys. Rev. 84, 717 (1951)

S 1 : Smith Damm, Phys. Rev. 90, 324 (1953)

E 2 : Ewald, Z.Naturforsch. 5a, 1 (1950) 
上述のごとく ${ }^{2} \mathrm{CH}_{4}-16 \mathrm{O}$ の質量差の開きの大なるこ とはこの二重線が質量補助標潐の最重要な $12 \mathrm{C}$ の質量 決定に決定的役割を持つているだけに重大事で，これ が質量分析より得られた原子質量值と核反分上りの。 のとが二重線質量差はほとんど一致しているにるかか わらずかなり大きな違いをあらわす最大原因となつて いる。したがつてこの ${ }^{12} \mathrm{CH}_{4}-16 \mathrm{O}$ の質量垒の確定は 現在原子質量測定において最緊急事となつている。

原子質量の決定はいづれにしても幾組かの二重線質 量差が測定されそれらの組合せよりまつ質量補助標準 の決定が行われることは周知のと扣りであるが，普通 基本二重線と呼ばれる次の三組の二重線が採られこれ らより ${ }^{1} \mathrm{H}, 2 \mathrm{D}$ および ${ }^{12} \mathrm{C}$ 質量が決定される。 寸なわち，

$$
\left.\begin{array}{l}
\mathrm{H}_{2}-2 \mathrm{D}=\alpha \\
2 \mathrm{D}_{3}-\frac{1}{2} 12 \mathrm{C}=\beta \\
12 \mathrm{CH}_{4}-16 \mathrm{O}=\gamma
\end{array}\right\} \text { 基本二重䠌 }
$$

これらから

$$
\begin{aligned}
& { }_{1 \mathrm{H}}=\frac{1}{16} 160+\frac{3}{8} \alpha+\frac{1}{8} \beta+\frac{1}{16} \gamma \\
& { }^{2} \mathrm{D}=\frac{1}{8} 16 \mathrm{O}-\frac{1}{4} \alpha+\frac{1}{4} \beta+\frac{1}{8} \gamma \\
& { }_{12 \mathrm{C}}=\frac{3}{4} 16 \mathrm{O}-\frac{3}{2} \alpha-\frac{1}{2} \beta+\frac{3}{4} \gamma
\end{aligned}
$$

として求められる。Nier 等は $12 \mathrm{C}$ の質量値の不一 致が ${ }^{12} \mathrm{CH}_{4}-16 \mathrm{O}$ にあることに注目この質量美を用いず に ${ }^{12} \mathrm{C}$ を算出するため, $16 \mathrm{O}_{2}-32 \mathrm{~S}, 12 \mathrm{C}_{4}-32 \mathrm{~S} 16 \mathrm{O}$ の二組の 二重線を用いたが，その結果は今のところ核反応より 得られた值と一致せず，上記基本二重線よりのものと 一致した結果を得ている。(しかし質量分析の方に招 いても Ewald の值は核反応よりのものとよく合つて いる。) しかし最近つ Mattauch, Bieri (1954); Smith, Damm（1953）紫の精密な実験結果に上ると ${ }^{2} \mathrm{C}$ $\mathrm{H}_{4}-160$ の值は質量分析 (Ewald 以外の) に上るも のと核反応よりのものとのほぼ中間にきているが，こ れらの点に関してはまだ今後にその確定は残されてい るといわねばならない。つぎに参考つため多くの質量 の基礎となる二三の二重線の質量美の測定値を図に示 しておく。

前記のごとく原子質量測定はその基礎となるすのは いうまでもなく二重線質量美であるのでまづ第 1 表に 戦後慎重な注意を厸つて測定したと考えられる結果を かかげ，第 2 表にそれらより算出された原子筫量值を かかげることにした。表中原子核反応とあるのは $\mathrm{Li}$ 等により核实験データより計算されたるのである。な

\begin{tabular}{|c|c|c|c|c|c|c|c|c|c|c|c|}
\hline \multicolumn{3}{|c|}{ 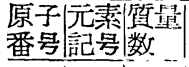 } & 二重 線 & $\begin{array}{l}\text { 憵 量 差 } \Delta \mathrm{M} \\
\text { (10-4 AMU) }\end{array}$ & 交 献 & \multicolumn{3}{|c|}{ 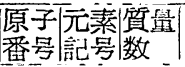 } & 二重線 & $\begin{array}{l}\text { 筧 量 羙 } \Delta \mathrm{M} \\
\left(10^{-4} \mathrm{AMU}\right)\end{array}$ & 文 献 \\
\hline \multirow[t]{5}{*}{1} & \multirow[t]{5}{*}{$\mathrm{H}$} & & $\mathrm{H}_{2}-\mathrm{D}$ & $15.519 \pm 0.017$ & (R 1) & \multirow{18}{*}{6} & \multirow{18}{*}{ C } & \multirow{4}{*}{11} & $10 \mathrm{BH}^{19} \mathrm{~F}-{ }^{11} \mathrm{~B}^{19} \mathrm{~F} \mid$ & $114.50 \pm 0.15$ & (O 1$)$ \\
\hline & & & & $15.503 \pm 0.015$ & (E 3) & & & & $10 \mathrm{BD}-12 \mathrm{C}$ & $270.16 \pm 0.20$ & $(\mathrm{O} 1)$ \\
\hline & & & & $15.492 \pm 0.008$ & (O1) & & & & $11 \mathrm{~B}-1 / 2^{22 \mathrm{~N}_{\mathrm{e}}}$ & $136.20 \pm 0.08$ & $\left(\mathrm{O}_{1}\right)$ \\
\hline & & & & $15.473 \pm 0.005$ & (M1) & & & & ${ }^{11 B H-12 C}$ & $171.15 \pm 0.06$ & (O 1$)$ \\
\hline & & & & $15.494 \pm 0.024$ & (N.D.2) & & & 12 & $D_{3}-1 / 3^{12 C}$ & $422.92 \pm 0.12$ & (E 3) \\
\hline \multirow[t]{8}{*}{2} & \multirow[t]{8}{*}{$\mathrm{H}_{\mathrm{e}}$} & \multirow[t]{8}{*}{4} & $\mathrm{D}_{2}-{ }^{4} \mathrm{H}_{\mathrm{e}}$ & $256.04 \pm 0.08$ & (E 2) & & & & & $423.01 \pm 0.09$ & (O 1) \\
\hline & & & & $256.12 \pm 0.09$ & (N1) & & & & & $423.254 \pm 0.051$ & (M1) \\
\hline & & & & $256.03 \pm 0.06$ & $(01)$ & & & & & $423.02 \pm 0.16$ & (ND2) \\
\hline & & & & $256.060 \pm 0.029$ & (M1) & & & & ${ }^{12} \mathrm{CH}_{4}-16 \mathrm{O}$ & $363.71 \pm 0.12$ & (E 3) \\
\hline & & & & $255.96 \pm 0.08$ & (ND 2) & & & & & $364.78 \pm 0.22$ & (N1) \\
\hline & & & $\mathrm{D}_{2} \mathrm{H}-{ }^{4} \mathrm{H}_{\mathrm{e}} \mathrm{H}$ & $256.074 \pm 0.025$ & (M1) & & & & & $364.27 \pm 0.08$ & (C 1$)$ \\
\hline & & & ${ }^{4} \mathrm{H}_{\mathrm{e}} \mathrm{D}-1 / 2^{12} \mathrm{C}$ & $167.141 \pm 0.034$ & (M1) & & & & & $364.15 \pm 0.08$ & (O1) \\
\hline & & & ${ }^{4} \mathrm{H}_{\mathrm{e} 2}-1 / 2^{16} \mathrm{O}$ & $77.543 \pm 0.044$ & (M1) & & & & & $364.086 \pm 0.038$ & (M1) \\
\hline 3 & $\mathrm{Li}$ & 7 & $7 \mathrm{Li}-1 / 2^{14 \mathrm{~N}}$ & $(144.3 \pm 1.0)$ & (B 1) & & & & & $363.72 \pm 0.19$ & (ND2) \\
\hline \multirow[t]{2}{*}{4} & \multirow[t]{2}{*}{$\mathrm{B}_{\mathrm{e}}$} & \multirow[t]{2}{*}{9} & ${ }^{9} \mathrm{~B}_{\mathrm{e}} \mathrm{H}-\mathrm{I0B}$ & $(69.4 \pm 2.0)$ & (J 1) & & & & \multirow[t]{2}{*}{$12 \mathrm{CH}_{4}-12 \mathrm{C} 16 \mathrm{O}$} & $364.43 \pm 0.22$ & (N1) \\
\hline & & & ${ }^{9} \mathrm{~B}_{\mathrm{e}} \mathrm{H}-1 / 2^{20 \mathrm{~N}} \mathrm{e}$ & $(239.1 \pm 2.0)$ & (J 1$)$ & & & & & $364.23 \pm 0.08$ & (O 1 ) \\
\hline \multirow[t]{2}{*}{5} & \multirow[t]{2}{*}{ B } & \multirow[t]{2}{*}{ I0 } & ${ }^{10 B}-1 / 2^{20 \mathrm{~N}_{e}}$ & $167.22 \pm 0.08$ & (O1) & & & & & $363.877 \pm 0.041$ & (S 1) \\
\hline & & & ${ }^{10} \mathrm{BH}-{ }^{11 \mathrm{~B}}$ & $114.47 \pm 0.14$ & (O1) & & & & ${ }^{12} \mathrm{C}_{3} \mathrm{H}_{8}-12 \mathrm{CO}_{2}$ & $729.68 \pm 0.44$ & (N1) \\
\hline
\end{tabular}
打第 2 表中同位体存在比は National Bureau of Standards より発行されている“Nuclear Data” り採録したものである。

第 1 表二重線 筧量差 


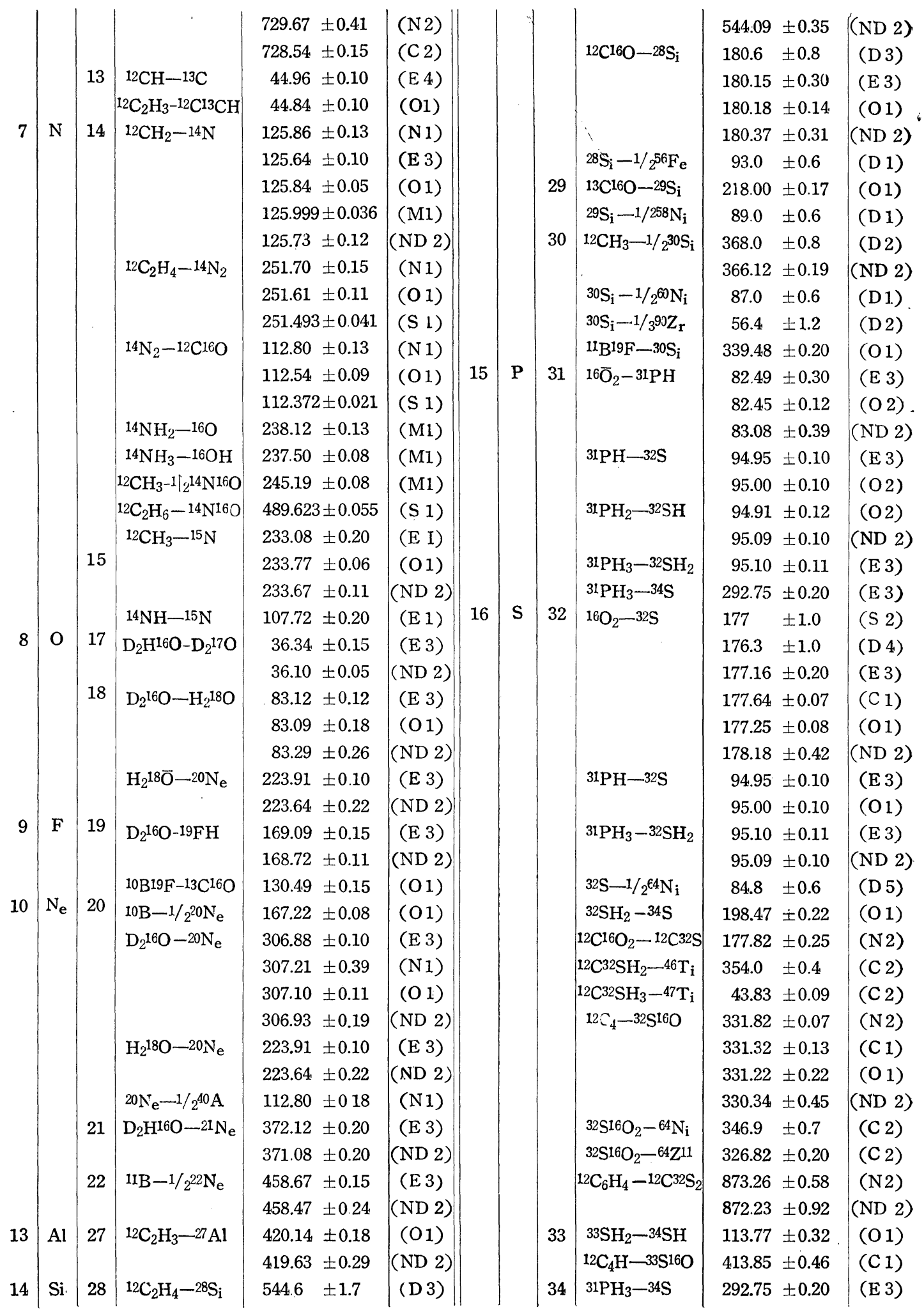




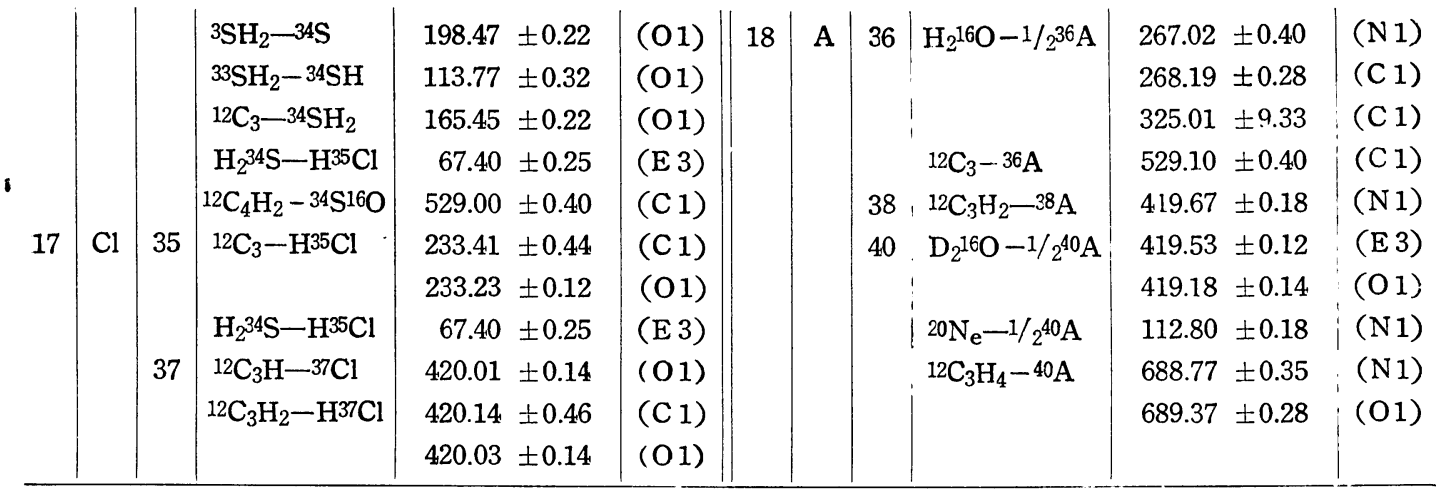

第 2 表 原子質 量

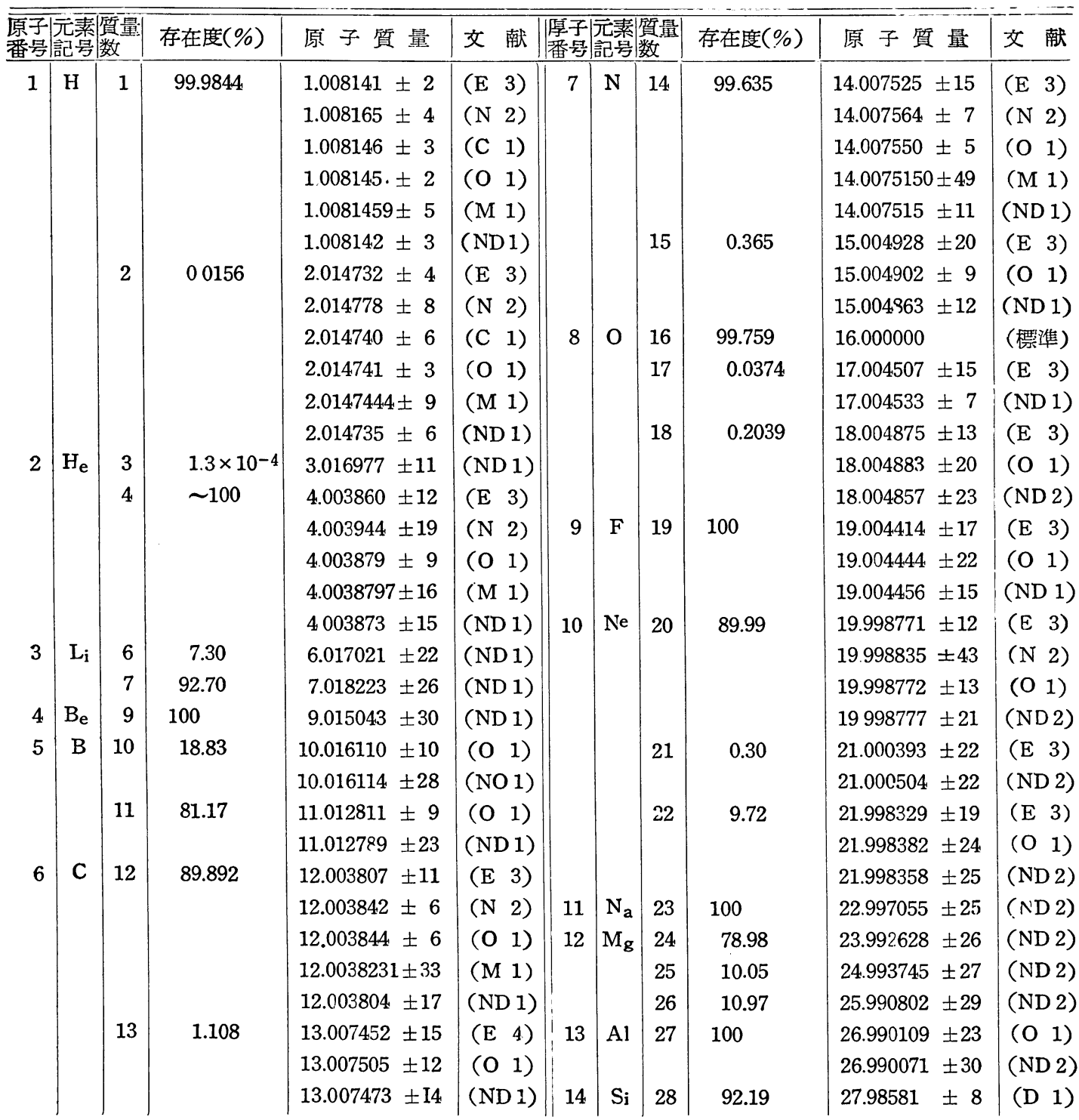




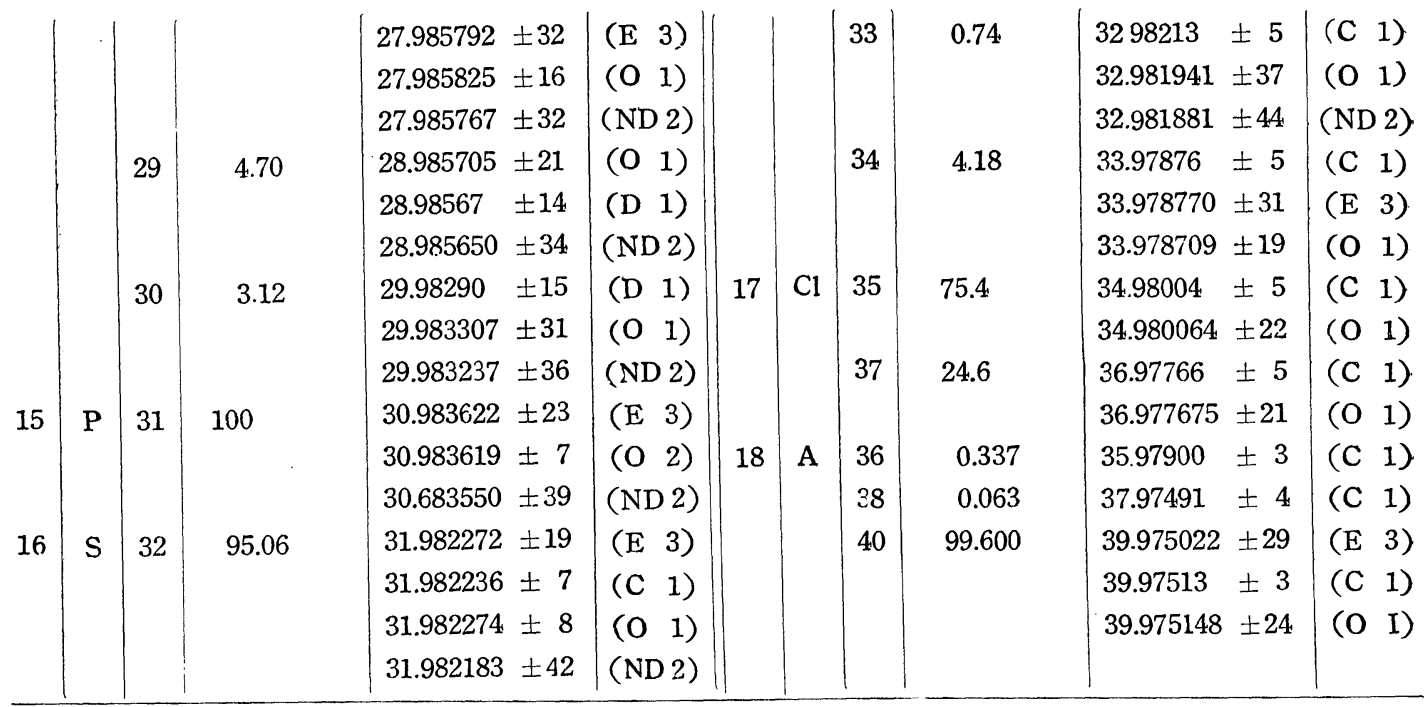

文献

(B 1) Bainbridge-Jordan, Phys. Rev. 51, 384 (1937)

(C 1) Collins et. al. , ibid 84, 717 (1951)

(C 2) Collins et. al. , ibid 86, 408 (1952)

(D 1) Duckworth et. al , ibid 78, 386 (1950)

(D 2) Duckworth et. al. , ibid 79, 188 (1950)

(D 3) Duckworth et. al. , ibid 79, 402 (1950)

(D 4) Duckworth et. al. , ibid 81, 286 (1951)

(D 5) Duckworth et. al. , ibid 83, 1114 (1951)

(E 1) Ewald , Zs. f. Naturforsch. 1, 131 (1946)

(E 2) Ewald, ibid 5a, 1 (1950)

(E 3) Ewald, ibid 6a, 293 (1951)
(E 4) Ewald, ibid 8a, (Heft 7) (1953)

(J 1) Jordan, Bainbridge, Phys. Rev. 51, 385 (1937)

(M 1) Mattauch, Bieri , 私信 (1954)

(N 1) Nier, Roberts , Phys. Rev. 81, 507 (1951)

(N 2) Nier, ibid 81, 624 (1951)

(ND 1) Li, Whaling, Fowler, Lauritsen, ibid 83, 512 (1951)

(ND 2) Li , ibid 88, 1038 (1952)

(O 1) Ogata, Matsuda, ibid 89, 27 (1953)

(O 2) Ogata, Matsuda , ibid 89, 333 (1953)

(R 1) Roberts , ibid 81, 624 (1951)

(S 1) Smith, Damm, ibid 90, 324 (1953)

(S 2) Smith (1951)

\section{質量スペクトル表 I}

\section{凡例}

ピークの種別 M/e の次に示す記号はピークの種

別をあらわす。

$\mathrm{p}$ ： parent peak (親イオン)

i ： 同位元素のみによるピーク

$\mathrm{d}: 2$ 価イオンによるピーク

$\mathrm{m}$ ：準安定イオンによるピーク $\mathrm{r} ：$ 再配列によるピーク

?: 不眀

$\mathrm{x}$ : 不純物

API: American Petroleum Institute Research Project 44 API の次の数字は serial number を示す

$\mathrm{T}$ ：東京大学綜合試験所内 CEC 21-103 A 型 質量分析計による測定結果 